\title{
Fire retardant performance of rice husk ash-based geopolymer coated mild steel - a factorial design and microstructure analysis
}

\begin{abstract}
Higher content of silica in geopolymer coating resulted in better thermal properties. Since rice husk ash (RHA) has the highest silica content compared to other aluminosilicate sources available, it offers the best potential to be an alternative silica source in producing geopolymer coating binder. In this study, five factors including ratio of alkaline activator (AA) (A), ratio of RHA/AA (B), curing temperature (C), curing time (D) and concentration of $\mathrm{NaOH}(\mathrm{E})$ were analyzed using statistical analysis to identify the significant factors that mostly influence fire retardant performance of RHA-based geopolymer coating. The fire retardant tests were conducted and results recorded included (i) time taken to reach $300^{\circ} \mathrm{C}$ and (ii) temperature at equilibrium. Sample $\mathrm{S} 7$ (coating composition of $\mathrm{A}=5.5, \mathrm{~B}=0.3$, $\mathrm{C}=50^{\circ} \mathrm{C}, \mathrm{D}=7$ days, $\mathrm{E}=8 \mathrm{M}$ ) which produced the best fire retardant performance was selected for further detailed investigation using thermogravimetry analysis (TGA) and scanning electron microscopy (SEM). It was found that the back temperature of mild steel plate of sample $\mathrm{S} 7$ reached $300^{\circ} \mathrm{C}$ after 17 minutes and achieved an equilibrium state at $398^{\circ} \mathrm{C}$. SEM micrographs showed the presence of needle-like structures formed after fire test might be the reason for the best fire performance of sample S7.
\end{abstract}

Keyword: Fire retardant; Geopolymer coating; Intumescent coating; Mild steel; Rice husk ash 